ISSN: 1130-3743 - e-ISSN: 2386-5660

DOI: http://dx.doi.org/10.14201/teoredu2016282163183

\title{
LA PEDAGOGÍA DEL OTRO: BASES ANTROPOLÓGICAS E IMPLICACIONES EDUCATIVAS
}

\author{
Pedagogy of the other: anthropological bases \\ and educational implications
}

\section{Pédagogie de l'autre: bases anthropologiques et implications éducatives}

Ramón Mínguez Vallejos, B. Eduardo Romero Sánchez y Marina Pedreño Plana Universidad de Murcia. Facultad de Educación.

Departamento de Teoría e Historia de la Educación.

Campus Universitario de Espinardo. 30100 Murcia.

rminguez@um.es; eromero@um.es; marina.pedreno@um.es

Fecha de recepción: enero de 2016

Fecha de aceptación: marzo de 2016

\section{RESUMEN}

El propósito de este artículo es analizar la antropología que subyace en el pensamiento de Emmanuel Lévinas como fundamento de la pedagogía del otro. Se comienza con la reflexión del otro como vía de acceso a la interpretación de lo humano. Se aportan argumentos que explican la crítica radical del yo como cogito y se descubren las características centrales de la antropología levinasiana: la relación con el otro como vía de construcción humana; esa relación es radicalmente heterónoma; la presencia del otro es una exigencia que se convierte en responsabilidad. Esta antropología inspira otro modo de educar que repercute en la relación del educador y del educando. Se indican las condiciones necesarias que el educador debe asumir desde esta nueva perspectiva educativa. Por último, se señalan dos valores que dan consistencia a la relación educativa: la práctica del diálogo y el aprendizaje de la compasión. 
Palabras clave: educación-antropología; educación-filosofía; educación-teoría; Lévinas; compasión; diálogo; responsabilidad.

\section{SUMMARY}

The purpose of this article is to analyze the anthropology that underlies the thinking of Lévinas as basis for the pedagogy of the other. To that aim, some of the basic elements of his anthropology are identified. The paper starts with the reflection about the other providing access to the human being interpretation. Arguments that explain the radical critique of the self as cogito and the main characteristics of Lévinas's anthropology are exposed: the relationship with the other as a means of human construction; that relationship is radically heteronomous; the presence of the other is a requirement that becomes responsibility. This anthropology inspires another education that affects the relationship between the teacher and the learner. The conditions that the educator must assume from this educational perspective are indicated. Finally, two values that give consistency to the educational relationship are identified: the practice of dialogue and the learning of compassion.

Key words: education-anthropology; education-philosophy; educational-theory; Lévinas; compassion; dialogue; responsibility.

\section{SOMMAIRE}

Le propos de cet article est d'analyser l'anthropologie qui sous-tend la pensée de Lévinas comme le fondement de la pédagogie de l'autre. Ici s'identifient certains des éléments de base de son anthropologie. Il commence avec l'étude de l'autre comme une passerelle vers l'interprétation de l'être humain. Ils sont donnés les arguments qui expliquent la critique radicale de soi-même comme cogito et les principales caractéristiques de l'anthropologie de Lévinas: la relation avec l'autre comme un moyen de construction humaine; cette relation est radicalement hétéronome; la présence de l'autre est une exigence qui devient à la responsabilité. Cette anthropologie inspire une autre façon d'éduquer qui affecte à la relation entre l'enseignant et l'apprenant. Les conditions que l'éducateur doit assumer dans cette perspective éducative ont indiquées. Finalement, deux valeurs qui donnent consistance à la relation éducative sont identifiées: la pratique du dialogue et l'apprentissage de la compassion.

Mots clés: éducation-anthropologie; éducation-philosophie; théorie de l'éducation; Lévinas; compassion; dialogue; responsabilité.

\section{INTRODUCCIÓN}

Resulta imposible iniciar cualquier tarea educativa sin considerar, de algún modo, la condición humana. Decimos de algún modo porque toda actividad 
educativa, ya sea explícita o más veladamente, se orienta hacia unos fines concretos que tienen que ver con un determinado modelo de hombre y de sociedad al que se pretende aspirar. Por tanto, lo humano y lo educativo son asuntos íntimamente relacionados y no tienen razón de ser el uno sin el otro. Y es que la educación es patrimonio del género humano y el hombre es lo que es gracias a lo que la educación ha hecho de él. Lo educativo adquiere coherencia e inteligibilidad cuando se logra rigor en la imagen de ser humano sobre la que se sustenta (Fullat, 1997). Sin embargo, algunos teóricos de la educación piensan que la reflexión pedagógica solo debe ser una generalización de la práctica, o que se deben rechazar reflexiones filosóficas conforme a los avances científicos (Escámez, 1981). Ambas posturas derivan en un tratamiento superficial de las cuestiones básicas de la educación. Por lo que, para educar, es necesario conocer los supuestos antropológicos de cualquier pedagogía si se pretende que este saber contribuya a la realización del proyecto humano.

Podría parecer un esfuerzo inútil seguir reflexionando sobre los textos de Lévinas ante la gran cantidad de estudios publicados sobre su obra a lo largo de los últimos decenios (Hand, 2009). Sin embargo, como Hanus (2012, 9 y ss.) sugiere, la actualidad de un pensamiento consiste en que sigue estando vivo porque lanza la pregunta ¿qué nos dice a nosotros? O el mismo Lévinas (2010, 195), a propósito del pensamiento de Maimónides, escribe «La valeur d'une vrai philosophie no se place pas dans une éternité impersonnelle. [...]. L'aspect véritablement philosophique d'une philosophie se mesure à son actualité». Inmersos en la tarea de seguir leyendo e interpretando a Lévinas, nos acercamos a su pensamiento como una filosofía actual que suscita una perspectiva enriquecedora de múltiples elementos aún por redescubrir.

La reflexión sobre lo humano desde la perspectiva levinasiana se presenta distinta porque centra su filosofía en una idea original de la subjetividad, caracterizada por la alteridad. Es el otro de quien tiene que responder el yo para constituirse como persona responsable. Esta visión de la subjetividad ha contribuido a que Lévinas sea considerado uno de "los filósofos más profundos y originales del siglo XX” (Hand, 1989, v).

Además, ha sido objeto de atención creciente entre filósofos y teóricos de la educación (Zhao, 2016). Y en sus textos se pueden encontrar "criterios y normas no para ser aplicadas a la educación» (Egéa-Kuehne, 2008, 2), sino como lectura reflexiva sobre algunos de los supuestos implícitos en educación. A tal efecto, en este trabajo se ha seguido el método fenomenológico de la antropología filosófica (Sahagún, 1996), cuya elección está motivada por el objeto a estudiar: la visión que Lévinas tiene del ser humano. Dado que la trayectoria del filósofo lituano fue coherente entre sus creencias judías, su pensamiento y su labor educativa como profesor universitario y director de la École Normale Israélite (Chinnery, 2010), exige un acercamiento amplio e intuitivo hacia el conjunto de su vida y obra.

Atenderemos a determinadas ideas claves de esta antropología, en tanto que produce un giro copernicano en la teoría y práctica educativa. En concreto nos 
referiremos a los principios inspiradores de determinados valores éticos que orientan la perspectiva pedagógica de la alteridad como reconocimiento y promoción del otro.

En ese sentido, lo humano no será entendido como aquella actividad del yo encerrada sobre sí mismo, sino como respuesta a la llamada de la alteridad. Para Lévinas, en este "salir de sí mismo" e "ir hacia el otro" comienza lo humano. El yo queda conmocionado por la llamada del otro que le obliga a responderle. Lévinas defiende una subjetividad responsable que no admite discusiones: soy responsable por el otro. Y esa responsabilidad es irremplazable, porque no lo decide libremente el yo, sino que le ha sido designado por la alteridad del otro. Solamente la inquietud sin límites de responder por el otro hará posible emerger lo humano en la vida de ambos.

La relación de uno-por-el-otro resulta inevitable para la constitución de lo humano, no reducida a un nexo extrínseco de "estar junto a" o "al lado de", sino como un estar ligado uno y otro, vínculo humano que en sentido propio quiere decir que solo quien responde por el otro es capaz de ponerse en interacción con su mundo, del que el otro forma parte intrínseca (Pieper, 2000). Al subrayar esta relación estamos concediendo primacía al otro alejándonos de una visión egocéntrica del yo que elimina cualquier atisbo de alteridad.

En el ámbito educativo, esta posición se inserta en el marco de una cultura de la solidaridad que busca lo valioso (lo bueno) y digno de ser vivido en beneficio de la calidad humana de la sociedad. El otro como educando convoca lo mejor de cada educador y apela a tomar como criterios orientadores de la tarea educativa la responsabilidad, la solidaridad, la igualdad o la justicia. En el fondo, nuestra reflexión pedagógica no comporta neutralidad ética e intenta poner al educando como centro del proceso educativo, no tanto dirigida a establecer "opciones» didácticas, sino a acentuar el carácter ético-moral de la educación.

\section{El OTRO, VÍA DE ACCESO A LA INTERPRETACIÓN DE LO HUMANO}

El pensamiento antropológico de Lévinas (2006a, 193) es el intento de comprender que "nuestra humanidad consiste en dar preeminencia al otro". De lo que se trata es del otro, de sus necesidades y de su vida, y al situarlo en el primer lugar estamos obligados a responder éticamente de él. Es la responsabilidad para con el otro lo que hace posible la humanidad del ser humano. Para ello, nuestro autor se aleja de construcciones filosóficas que han predominado en nuestro pensamiento occidental y evoca experiencias cotidianas que ponen al descubierto situaciones inhumanas. En efecto, hay un "sufrimiento inútil» de seres humanos en la historia del mundo, de «desheredados, marginados, disminuidos en sus relaciones vitales y en su contacto con los demás» (Lévinas, 2001, 117), que pone al descubierto el principal problema humano: la violencia ejercida contra el otro es una constante en la historia de la humanidad. 
Sin embargo, la responsabilidad por el otro aún está lejos de ser una realidad irrevocable en nuestro mundo. Si miramos a nuestro pasado más reciente se nos presenta un escenario de fuertes contrastes. Mientras que millones de seres humanos disfrutan de unas condiciones de vida altamente satisfactorias a causa del desarrollo científico y del crecimiento económico (Sachs, 2011), otros se han visto postergados a numerosas situaciones de desigualdad, pobreza e injusticia ocasionadas por seres humanos hacia su semejante.

En nuestro mundo globalizado, donde parecen haber desaparecido las barreras entre países y personas, se alza un difuso dinamismo de indiferencia hacia los más desfavorecidos. Una mentalidad hiperindividualista y de claro consumismo egoísta se ha extendido en amplios sectores de la sociedad occidental. Según Marzano (2011), lo que triunfa en esta sociedad es la cultura del autoéxito y de la autorrealización, en cuyo seno crece la sensación de que si el otro no alcanza mejores cotas de bienestar humano es porque es incapaz de convertirse en "empresario de sí mismo». Con ello nos hemos habituado a contemplar como «espectáculo» el sufrimiento del otro. Vivimos en sociedades interesadas donde los vínculos sociales se debilitan y la convivencia humana es reflejo del pragmático y egoísta mercado de bienes y servicios.

Algunos autores han pretendido ver en esta situación la visión cainita del ser humano, imagen que lleva a la violencia, dominio y sumisión, cuando no a la eliminación del otro ser humano. El crecimiento de interdependencias e interacciones a escala mundial entre seres humanos no ha logrado aún el deseado hacerse prójimo del otro como base de una sociedad justa y pacífica. Tampoco lo consiguió la Modernidad. Lo que se presentó entonces como un proceso de liberación del hombre a través del uso de la razón ha llegado a convertirse en todo lo contrario. Del deseo de una sociedad integrada por seres humanos libres e iguales, han surgido con el tiempo nuevos modos de manipulación del "hombre por el hombre». Del ideal moderno de emancipación del ser humano de toda esclavitud, se ha llegado a que la razón sea el principal instrumento de dominio y explotación del otro humano. Con esta mentalidad instrumental que antepone el cálculo y el beneficio propio frente a la dignidad del ser humano, el otro se ha convertido en algo prescindible y desechable. Ante esta tozuda realidad, es necesario buscar el significado y sentido no instrumental de la relación del ser humano con el otro.

Recurrimos al pensamiento de Lévinas porque en su discurso percibimos una clara contraposición entre dos posiciones antropológicas: la egológica, que interpreta al ser humano como individuo soberano-solitario, orientado por la voluntad de poder y el mito de la totalidad (Lévinas, 2002); la segunda posición consiste en la primacía del otro como criterio fundamental para constituirse como ser humano (Lévinas, 2003). Mientras que la primera posición ha predominado en el pensamiento de Occidente y ha reducido la realidad a lo pensado por el yo, la segunda quiere expresar la singularidad del otro como resistencia a ser absorbido por el yo y convertido en un objeto deshumanizado. Es el otro y no el yo el que hace posible la apertura a lo humano. 


\subsection{El otro}

Hasta no hace mucho tiempo el otro no era pensado como algo distinto del yo, un alter ego, porque lo común de ambos residía en su capacidad de razonar (Soffer, 1999). Sin embargo, comienza a adquirir mayor relieve la cuestión del otro cuando la reflexión antropológica se aleja de la visión abstracta de la humanidad y centra su atención en el ser humano concreto. Las palabras de Unamuno (1958, 729) reflejan con bastante precisión el giro antropológico producido: «Ni lo humano ni la humanidad, ni el sustantivado, sino el sustantivo concreto: el hombre. El hombre de carne y hueso, el que nace, sufre y muere..., piensa y quiere, el hombre que se ve y a quien se oye».

Es la preocupación por el ser humano concreto lo que ha prevalecido en la reflexión antropológica desde mediados del siglo pasado (Descombes, 1988). Y en particular el encuentro con el otro, el tú, ocupa un lugar preeminente en la reflexión antropológica contemporánea, porque de lo que se trata es de la posibilidad de decidir "entre tratar a los otros como un mero medio para mis propios fines, o de relacionarme con los otros con la lucidez de que cada otro es siempre una realidad dignísimamente absoluta” (García-Baró, 2012, 23).

El pensamiento de Lévinas gira en torno al estudio del otro y constituye la aportación más original de su filosofía (Derrida, 1989). No sigue «la sabiduría de la tradición y del pensamiento occidental» (Lévinas, 2001, 222), sino que se presenta como un crítico del totalitarismo de la razón y del centralismo del sujeto. Con ello, no se abstiene de la razón y cede al irracionalismo, ni tampoco se desprende del sujeto. Aporta, sin embargo, nuevas coordenadas que suponen un cambio en el modo de pensar el problema de la sociabilidad y el de la intersubjetividad. Desde una determinada tradición judía, nuestro autor sitúa al otro en el centro de su pensamiento y lo convierte en la temática fundamental de su antropología (Beorlegui, 1998).

De entrada podría preguntarse si la obra de Lévinas no es sino una crítica de la egología cartesiana y de la fenomenología de Husserl y Heidegger, donde plantea la cuestión del sujeto como un 'ir hacia el otro'. Este movimiento se inicia con la ruptura del yo tranquilo consigo mismo, de ese ser egoísta que es perturbado por la irrupción del otro. Podría quedar resumida la crítica levinasiana en la conocida frase de P. Celan: "Yo soy tú cuando yo soy yo». En diferentes textos Lévinas insiste en la misma idea: el nacimiento de un sujeto responsable del otro. Este cambio de pensamiento queda explicitado en el modo que concibe la idea de responsabilidad. Desde la tradición, responsabilidad se ha identificado como autorresponsabilidad. Tanto al hablar como al actuar, el yo responde de sí mismo. Por lo que dar razón de lo dicho o hecho ante cualquiera es lo que caracteriza al sujeto como (auto-)responsable. En este sentido, el sujeto es autónomo; sigue sus propias normas que se impone a sí mismo. Sin embargo, Lévinas se centra en la responsabilidad por el otro. Este cambio no surge de dar razón, sino «del responder a interpelaciones/pretensiones de otro, responder que se presenta como una forma de entrega" (Waldenfels, 2015, 261). La responsabilidad es ahora asumida como respuesta. No procede de ninguna decisión previa, intencionalidad o conciencia, 
sino de una experiencia previa por la cual estamos afectados y con ella "aparece una responsividad, es decir un responder» (Waldenfels, 2015, 287). No podemos no responder en el contexto de la responsividad levinasiana.

Desde este marco, el yo es exposición al otro a quien no puede esquivar: heteronomía. En otros términos, el sujeto se constituye no sólo en relación con el otro, sino también por la substitución del otro en el yo, rompiendo así cualquier posibilidad de que el sujeto logre su identidad en sí mismo. El yo se constituye por la exposición a la alteridad del otro. La "revolución copernicana» del pensamiento levinasiano es el descubrimiento de que el yo se vuelve protagonista del otro y no a la inversa (Lyotard, 2015).

En la antropología levinasiana el otro se resiste a ser objeto del «yo pienso», a quedar sometido a su poder. Entonces, el yo establece una relación de desigualdad respecto del otro: el yo es rehén del otro. Siendo consecuente con este planteamiento, Lévinas insiste en que frente a cualquier intento de que el otro pueda quedar atrapado por la razón o tematizado por una imagen-idea, el rostro del otro excede a cualquier descripción posible.

El tema del rostro es un modo de criticar la posición central del yo como sujeto capaz de emitir juicios y valoraciones. Pero ¿qué es rostro?, ¿qué significa? El rostro no se puede definir porque, al hacerlo, se convertiría en lo que no es. "El rostro no se puede comprender, contenerse ni reconocerse; provoca una grieta ética» (Mèlich 2014, 321). O también como afirma Chalier $(1995,79)$ «percibir un rostro es algo que se vive como un sobrecogimiento que no deja tiempo para mirarlo al modo como se contempla una imagen». No se accede al rostro mediante la imagen o la visión, sino por la escucha. El otro, como rostro, es un encuentro que no se anuncia, ocurre; lo cual es descrito como un acontecimiento que sorprende al sujeto, le sobrecoge y le aviva a responder de él. En otros términos, soy yo quien tiene que responder del otro. Por eso, el rostro del otro descentra al yo y expresa que hay un más allá de lo determinado por el yo.

Con la expresión "rostro del otro" Lévinas se refiere a "lo que identifica al otro... en su expresión desnuda” (Poiré y Lévinas, 2009, 27). Y, en otro lugar, el filósofo lituano escribe: «El otro es el único a quien puedo matar. Pero este poder es todo lo contrario del poder. [...] Estar en relación con otro cara a cara es no poder matar» (Lévinas, 2001, 21). Al hablar de ese modo, lo hace insistiendo en su carácter más vulnerable y expuesto a las violencias humanas. Es la parte más desnuda del ser humano, carente de protección, que plantea la posibilidad de asesinar al otro o la prohibición de ceder a tal tentación. Lo que en el fondo ofrece Lévinas cuando usa «el rostro», a juicio de Butler (2006, 20), es «una concepción de la ética basada en la aprehensión de la precariedad de la vida, que comienza con la vida precaria del Otro». El rostro comunica tanto la vida precaria como la prohibición de la violencia.

Dicho así, la violencia que elimina la vida humana evoca temor y angustia, pero la respuesta ética es el intento de evitar que tales sentimientos se conviertan en gesto asesino. Entendido de este modo, el rostro levinasiano no precisa de un 
rostro humano, aunque comunique lo vulnerablemente humano. Como afirma Mèlich $(2014$, 325), "lo importante del rostro es la demanda de responsabilidad y de compasión, la expresión de su precariedad y de su vulnerabilidad». Por lo tanto, el encuentro con el rostro del otro tiene una profunda carga de compasión que determina la orientación y medida del comportamiento humano. No hay posibilidad alguna de que el ser humano pueda ser y realizarse en el mundo si no es asumiendo su irrevocable responsabilidad de convertirse en respuesta al prójimo. Además, como afirma Lyotard $(2015,117)$, «lo que hace que los hombres sean semejantes es que cada uno lleve en sí mismo al otro». Asumir al otro no obedece a ninguna conciencia o juicio moral previo que le obligue a actuar por cumplimiento de un deber. Es respuesta a un pathos, afectado por algo que duele y mueve a responder ante la interpelación del otro, que no depende de la voluntad o intencionalidad, de donde emerge la comprensión de la experiencia, acción o lenguaje humano (Waldenfels, 2015).

En tanto que el sujeto levinasiano no puede desprenderse de su condición de rehén del otro, se sabe ya responsable del otro antes de que éste le formule pregunta alguna. El otro «me» es asignado antes de que el yo decida, por lo que ya ha sido elegido de antemano a responder de él, aun a su pesar. El otro no tiene sólo la capacidad de dar un nuevo significado al yo, sino que también le otorga una nueva identidad: la responsabilidad por el otro destruye toda posibilidad de encerramiento en el yo, a la vez que abre a un mundo con otros.

\subsection{La relación con el otro}

A la luz de las reflexiones anteriores resulta bastante evidente que el yo no puede engendrar en sí mismo la alteridad sin el encuentro con el otro, ni tampoco comprenderlo desde sus propias categorías mentales. La relación con el otro, el encuentro, es la única salida del yo hacia fuera, "hacia lo imprevisiblemente otro, sin esperanza de retorno" (Derrida, 1989, 129).

Salir de sí es un tema fundamental. Para nuestro autor, la salida de sí mismo es «el descubrimiento del fondo de nuestra humanidad, el descubrimiento mismo del bien en el encuentro con el otro... y la responsabilidad por el otro es el bien» (Poiré y Lévinas, 2009, 76). Es la única salida que le queda al yo para evadirse del anonimato, del horror de la soledad del sujeto pensante (Lévinas, 2000); salida de sí que es ocuparse del otro, responderle por mandato.

La apertura hacia el otro no es una simple exposición a sentirse afectado por él. "La apertura es la vulnerabilidad de una piel ofrecida..., más allá de todo lo que puede mostrarse, de lo que puede exponerse a la comprensión" (Lévinas, 2005, 122). Esa vulnerabilidad que prohíbe matar y obliga a preocuparse por el otro no puede impedir el sentirse apelado por una fuerza superior a mi voluntad. Por lo que mi relación con él no se origina en ningún acto de la conciencia, sino por algo que le precede: soy responsable del otro sin haber tenido tiempo de preguntar, de discutir nada, ni de haber dado mi consentimiento. Antes de la libertad del 
individuo está la responsabilidad. A este respecto escribe Chalier (1995, 59), «lo que aquí se esboza es una dimensión de la pasividad: el elegido no puede rehuir de su responsabilidad. Ésta le persigue allí a donde él se retire, y no le permite vivir tranquilo». Esta pasividad no es incapacidad para decidir. Significa designación, ser elegido para responder del otro. Tampoco esa pasividad constituye una impotencia o inercia para actuar, sino la afección que lo vuelve vulnerable ante la debilidad del otro y le obliga a responder de él. La "designación» para servir al otro descansa en esa pasividad que lo convierte en "guardián de su hermano». Lévinas llega a decir que esa pasividad no autoriza tranquilidad alguna, porque lo hace rehén de su prójimo. En esa designación descansa otra de las ideas centrales que define al ser humano: ser entre hombres y mujeres que no pueden desligarse unos de otros para vivir de modo humano.

La responsabilidad por el otro constituye en el pensamiento levinasiano un deseo insaciable y una exigencia que nunca acaba. Butler $(2009,127)$ expresa que la responsabilidad no depende de la voluntad, sino de un sentimiento no elegido que obliga a responder al otro: "Haya hecho este lo que haya hecho, me plantea, con todo, una exigencia ética, ante la cual estoy obligado a responder, y ello significa que estoy, por decirlo así, impedido de vengarme en virtud de una relación que nunca elegín. El otro es como un enigma insoluble que se me impone y que no reposa sobre ningún compromiso previamente contraído por mi libertad o mi conciencia.

A esta anterioridad no elegida surge la pregunta: ¿Por qué a mí? ¿No resulta una carga excesiva? Quien intentase buscar explicaciones ante tales interrogantes estaría, en palabras de Waldenfels $(2015,262)$, "presuponiendo que prevalece el interés propio o la autoconservación». O como dice Chalier (1995, 60), nuestro autor desoye esa "llamada a la moderación y a la medida, no consiente ser "más razonable" y dejar caer el peso de un mundo que, con frecuencia, va a la deriva; no se cansa de enseñar que la responsabilidad no se limita». La responsabilidad por el otro no es agradable, es como un «ir contra corriente», porque implica el esfuerzo y la renuncia a mi yo, aun a mi pesar; obliga infinitamente, porque nadie puede sustraerse de quien ha sido designado a ser responsable del otro; tampoco puede ser eximido de tal responsabilidad porque el elegido es insustituible de tal carga.

En el punto de partida de la responsabilidad para con el otro está el «cara a cara", un espacio de relación en el que el yo se siente afectado por la llamada del otro. "Desde el momento que me mira, yo soy responsable de él» (Lévinas, 2000, 80). En un primer momento, la relación con el otro parece que se fundaría en una simetría en la que el yo y el tú son responsables uno del otro. Pero Lévinas rechaza este fundamento y propone una asimetría fundamental para que no se retrase la llegada de lo humano. Chalier $(1995,87)$ señala que este desequilibrio de responsabilidad se funda en la idea de que "mi inquietud por el otro no depende de ninguna manera de su eventual preocupación por mí». Si espero a que el otro se preocupe por mí para responderle, nunca habría respuesta porque estaría esperando que el otro me devolviera lo que le he dado. Con la aparición del otro, el yo descubre que no es libre, sino responsable y de inmediato se le despierta la urgencia de 
un quehacer sin demora. Es un hospedar que adopta varias modalidades: acogida y servicio al otro; donación por lo que yo doy; renuncia a favor del otro; justicia como reconocimiento del otro y búsqueda del bien del otro.

Lévinas defiende la asimetría fundamental entre el yo y el otro como un modo de ser que escapa al interés de dar o recibir de modo retributivo y recíproco. La responsabilidad por el otro es altruismo sincero que lleva en su interior la idea de salir del propio yo, salida necesaria de sí mismo hacia una nueva manera de vivir: para el otro. Insiste Lévinas en que el hombre está abocado a salir de sí mismo: "La relación con el otro me cuestiona, me vacía de mí mismo y no cesa de vaciarme al descubrir en mí recursos siempre nuevos. No me sabía tan rico, pero ya no tengo derecho a guardarme nada» (Lévinas, 2005, 56).

En tanto que el otro se presenta ante el yo como una realidad que no depende de él, ni en su existencia ni en su configuración de sentido, el yo se convierte en "rehén" del otro, quedando a disposición de él. Y aquí se encuentra el nudo de la relación interpersonal: el uno-para-el-otro. Más en concreto, quiere decir que uno debe dar al otro, "es el ser que se deshace de su condición de ser: el des-inter-és» (Lévinas, 2000, 84). Pero insiste en que sólo se puede hacer cargo del otro el ser humano concreto, quien es cuerpo y sensibilidad, nunca el ser humano tomado como pensamiento. "La subjetividad humana, dice Lévinas (2006b, 226), es de carne y hueso". Esta constatación resulta especialmente sugerente al identificar la subjetividad con la sensibilidad.

Lévinas pretende replicar que frente a la razón, sensibilidad, y frente a la intención de representar en idea al otro antepone la pasividad respetuosa. Sensibilidad entendida como que el ser humano es un ser-en-el-mundo. Lo sensible para Lévinas no es interpretado en su acepción "natural", sino que vivimos en este mundo vinculados con otros seres humanos. Esta convivencia apela al reconocimiento y a la promoción conjunta en la realización de un espacio sociocultural en el que sea posible construir un mundo con rostro humano.

Además insiste en atender al otro concreto, al prójimo, el que está cerca o lejos. Ésta es la respuesta del que se sabe responsable del otro de tal modo que, en ningún momento, dicha respuesta queda anclada en explicaciones universalizables o en imperativos incondicionados. Tampoco esa respuesta es una simple emoción piadosa o una especie de suavizante de la conciencia que se manifiesta con evidente frialdad e indiferencia, sino de un claro sentimiento de compasión por la suerte del otro. Esta exigencia para con el otro no queda limitada al encuentro cara a cara, sino que también va ligado a un tercero. No basta la responsabilidad hacia ese otro concreto, inmediato y próximo, sino a cualquier otro indistinto en el tiempo (pasado, presente o futuro).

\section{3. ¿QUÉ SIGNIFICA UNA PEDAGOGÍA DEL OTRO?}

No resulta fácil traducir el pensamiento de Lévinas a una pedagogía del otro. Como decíamos al comienzo de este trabajo, no consiste en una simple tarea de 
"aplicar» sus ideas a un lenguaje pedagógico y convertirlas, sin más, en una propuesta educativa, sino que exige una tarea de mayor calado intelectual porque ha puesto en tela de juicio los fundamentos de nuestra tradición educativa occidental.

Así pues, la relación entre Lévinas y la educación no es una simple cuestión de transferir sus ideas al mundo educativo, sino ir acotando un nuevo modo de pensar la educación inspirándose en su filosofía (Joldersma, 2014; Strhan, 2012). Es como si Lévinas nos invitase a revisar lo que creemos, pensamos y hacemos en educación a la luz de su pensamiento. Compartimos la idea de Biesta $(2008,207)$ de que acerca de Lévinas "hay siempre mucho más que decir, porque de la sola lectura no se sigue un programa educativo claro, ni tampoco podrá ser implementado por educadores bien formados». Así pues, lo que sigue no es otra cosa que el esbozo de algunas propuestas aún pendientes de sistematización pedagógica y de praxis educativa.

Durante mucho tiempo, la teoría y la práctica educativas han estado orientadas desde unos presupuestos antropológicos distintos a aquellos de los que ha partido Lévinas. En la educación occidental, la visión del hombre como animal racional ha determinado las ideas sobre el qué, el cómo y el para qué educar. Así, desde hace más de dos siglos la educación ha sido concebida como un proceso dirigido a la formación de una persona "ilustrada", libre y autónoma. En términos amplios, educar se ha identificado con la consecución de un ser humano gobernado por la razón, cabal en sus juicios y en sus decisiones morales. A fin de cuentas, estar educado ha sido sinónimo de un individuo libre, autónomo y de juicio independiente.

Esta concepción de la educación ha estado vinculada directamente con la idea de sujeto como ego, es decir, un individuo encerrado en sí mismo que establece relaciones de conocimiento con el mundo y con los demás, con la ayuda de la ciencia y la técnica modernas. Además, se afirma que el sujeto humano está educado cuando es capaz de darse a sí mismo la ley moral, «en cuanto que se determina exclusivamente por la razón» (Kant, 1990, 101), con lo que se sustrae del dominio de cualquier causalidad empírica o trascendente, de modo que su conducta es moral cuando descansa en la autonomía de su voluntad.

Así pues, en la teoría y la práctica educativas se ha atendido más a la razón como característica definitoria del ser humano que a otras dimensiones como los sentimientos o las emociones. Sin embargo, hoy ya sabemos que la dimensión cognitiva, siendo importante, no es exclusiva ni siquiera determinante para explicar la totalidad del ser humano. Ello ha impulsado a que, al menos desde la teoría educativa, se haya producido una evolución de la "tradicional definición del ser humano como ser racional... a la consideración del hombre como el ser que piensa, siente y actúa, manifestaciones íntimamente ligadas entre sí y que no pueden pensarse aisladamente» (Prieto, 2011, 127).

Sin embargo, aún se sigue otorgando protagonismo a la idea de ser humano como dotado de razón. La absolutización del yo como sujeto pensante ha imposibilitado el desarrollo de acciones educativas superadoras de la visión intelectual del ser humano y ha obstaculizado el encuentro con el otro humano concreto 
y singular. Y es precisamente esta concepción de la subjetividad lo que ha sido cuestionado por Lévinas. En cierto modo, lo que hemos desarrollado en páginas anteriores recoge con cierta amplitud la crítica levinasiana al carácter egológico de la subjetividad.

Pero Lévinas va más allá de la crítica de la visión egológica y analiza a la cultura de Occidente de la que la educación ha sido un ingrediente fundamental en su perpetuación. Por ello, las críticas dirigidas a la cultura son también extensibles a la educación. En principio, toda la cultura occidental se ha interpretado como el saber que ha florecido con el desarrollo de las ciencias y las técnicas, proporcionando así un bienestar material hasta ahora desconocido a un amplio sector de la humanidad (Masschelein y Simons, 2013). Steiner (1998) critica duramente este "progreso" que no ha sido capaz de impedir las terribles tragedias del siglo pasado. Y éstas no han sido fruto de fuerzas incontroladas de la Naturaleza, ni de la casualidad ni de hombres ignorantes, sino de personas bien instruidas y cultas. También Lévinas se sorprende de que las instituciones y las personas se preocupen más de los avances científicos y tecnológicos que de la vida singular de las personas. "Cultura universalmente significativa como, en la modernidad, lo es la del saber y la técnica... pero es una cultura en la que el rostro del otro no despierta» (Lévinas, 2001, 216).

Si la educación hasta ahora ha prestado más atención a la transmisión del saber científico y ha dejado al margen otros acontecimientos más cotidianos de la vida de las personas, no resulta extraño que exista en nuestra civilización una creciente anonimización del ser humano. Sorprende cómo entre nosotros, por ejemplo, se conceda más atención a la crisis financiera y económica, preocupada por la ganancia y rentabilidad, y se siga asistiendo como si fuera algo pasajero al éxodo de millones de personas que huyen de la guerra y del hambre. Más aún, la crisis actual de la educación ha puesto de relieve la fractura de su tarea humanizadora, porque se ha buscado la satisfacción inmediata de unas necesidades creadas por la sociedad de consumo, desatendiendo las aspiraciones más valiosas del ser humano. Nos hemos dejado seducir por quienes dicen que lo más importante en la vida es aprender a ganar dinero porque con él se tiene todo. Se ha aprendido a vivir bajo la perspectiva economicista, donde poco importa si nuestros semejantes sufren esto o aquello injustamente. Estamos inmersos en una educación que apenas atiende a las capacidades expresivas del ser humano; una educación apática, donde aquello que nos llama la atención y nos lastima, con frecuencia, es pensado en forma de distracciones pasajeras y de apariencia inofensiva, donde educar se hunde en la monotonía de la in-diferencia.

\section{1. ¿Educar de otro modo?}

Aquí nos situamos en otro discurso educativo ajustado a la antropología de Lévinas y a la ética de la compasión (Mèlich, 2010). Si habitualmente se ha educado sin hacerse cargo del otro (educando), sin atender a su singularidad, es lógico que la tarea educativa se haya centrado en la transmisión de conocimientos, y que el 
otro haya sido también objeto de conocimiento, no de reconocimiento. Por eso la acción educativa se ha desarrollado de espaldas al otro concreto, alejada de lo que acontece en la vida de los educandos. Reconocer al otro es el intento de articular una perspectiva educativa hasta ahora poco atendida, similar a lo que el prof. Bárcena (2012) ha denominado "pedagogía de la presencia» en la que el espacio educativo está configurado por la experiencia concreta entre el maestro y el alumno.

En el fondo, estamos intentando revalorizar la dimensión ética y los aspectos afectivos de la educación, la necesidad de fortalecer los vínculos humanos que han sido considerados contenidos educativos de segundo orden. Pero ello no debería conducir a un nuevo desequilibrio, sino a un punto de inflexión en el que la atención al otro, el sentimiento de responsabilidad hacia él constituyan ingredientes básicos e imprescindibles para abordar la tarea educativa. Lejos de una formación instrumentalizada al servicio de una cultura individualista, la pedagogía de la alteridad es planteada aquí como una praxis educativa, en la que el educador se hace responsable del otro (educando) para que llegue a ser alguien valioso.

\subsection{El educador (y el educando) en la pedagogía del otro}

Educar desde esta perspectiva significa responder al y del otro (educando) en su tiempo y en su espacio. La persona necesitada de mí es lo primero que importa dentro de la pedagogía de la alteridad, y es él a quien el educador está obligado a responder (Ortega, 2010). El rasgo básico del educador en esta pedagogía es ser responsable del otro, estar obligado a responder a su demanda (Mínguez, 2012). Y esta responsabilidad se traduce en una actitud de atención y cuidado del otro, de desvivirse por él y de comprometerse por su suerte. Dicha actitud no es otra cosa que el comienzo de un nuevo despertar a una nueva racionalidad. El mismo Lévinas la describe apoyándose en G. Marcel (2001, 82): «Es sin duda necesario reaccionar con fuerza contra la idea clásica de la autarkia, de la suficiencia de sí mismo para sí mismo. Lo perfecto no es lo que se basta a sí mismo..., parece que debe darse un despertar». Lo que cuenta pues es la relación de uno con el otro, del educador con el educando, una relación no fundada en la idea de respeto abstracto, ni tampoco en una reciprocidad (yo-tú), sino en un despertar con lo distinto de sí mismo, con el otro. Y ello significa acoger al otro "con los brazos abiertos» (ibídem, 83). Se trata de que el educador despierte ante la necesidad del otro-educando, que no es sinónimo de encerrarse sobre sí mismo o abstraerse de la realidad concreta del alumno, sino que significa hospedar al otro hacia su realización gozosa como ser humano. O dicho en términos educativos, es generosidad incondicional de dar lo que necesita el otro-educando sin que, en ningún momento, nadie pueda decir que ha cumplido con su deber de educar. El educador responde del otro con responsabilidad ilimitada que sobrepasa a cualquier legalidad. Estamos, pues, ante otro modo de pensar y hacer la educación.

El punto de partida de la relación educativa es el encuentro, el "cara a cara" en el que la sola presencia del educando impide al educador la posibilidad de 
esquivarle. Hay dos ideas clave en la relación educativa a considerar: el educador ha sido elegido para ser el responsable del otro educando y, en tanto que es así, sustituido por el otro. Ser responsable es una exigencia que se impone antes de cualquier elección y nunca se deja de estar en paz respecto del otro; ser sustituido no significa ponerse en el lugar del otro, sino sacrificarse por él sin heroísmo ni orgullo. Momento irrepetible, en el que el otro-educando entra de modo "violento" en la vida del educador, quedando comprometida su palabra y acción educativa. Pero no es encuentro basado en la reciprocidad. Es relación a distancia, pero acogedora. Es alteridad en su sentido más radical, donde el educador siempre está frente al educando obligado a ser su servidor. Es una relación asimétrica, porque el educador es responsable del educando sin esperar una respuesta recíproca de él. Por eso hay un desequilibrio permanente en la relación educador-educando dentro de la pedagogía de la alteridad: "Yo soy responsable del otro sin esperar la recíproca, aunque ello me cueste la vida” (Lévinas, 2001, 82).

Siendo coherentes con estas ideas, cabe establecer que lo primero en la relación educativa es atender a la demanda que viene del otro/alumno. De ahí que la principal motivación del comportamiento del educador sea estar obligado a responder en concreto; es decir, antes de nada el comportamiento del educador es ético o responsivo, como lo caracteriza Waldenfels (2015). Planteado de este modo, el educador es quien se acerca al otro educando para dar comienzo a la tarea educativa. Pero esta tarea precisa de otras condiciones necesarias:

- Salir de sí mismo: No resulta sencillo «despojarse» de nuestra altura moral como maestros cuando nos acercamos al educando y, menos aún, descender al lugar en el que se encuentra el alumno. El otro me exige salir de mí y ponerme a la escucha para asumir como mía su situación. Es el educador a quien se le exige tomar la iniciativa de salir de sí mismo e ir hacia él, no recibirlo de modo pasivo o indiferente. Qué duda cabe de que la salida de sí mismo supone un riesgo, porque surge el temor a verse utilizado por el otro. Sin embargo, el educador está obligado a acoger y hospedar al otro. No puede ni debe anteponer sus sentimientos y aspiraciones personales. Debe darse al otro desde una actitud de servicio. La salida de sí mismo es la respuesta a la esperanza del otro, no al deseo de ser sí mismo.

- Acercarse a la realidad del otro: No hay educación si el educador no atiende a la circunstancia en la que vive el otro. No se trata de conocer el contexto del alumno como excusa para que parezca que el maestro se ajusta a su realidad. Solo cuando se educa desde el aquí y el ahora de cada educando, vinculado a su circunstancia personal, podrá haber educación y no otra cosa. Por ello, es condición básica que la acción educativa esté centrada en la persona del educando. A consecuencia de esto, el educador se hace presente cuando se acerca a la realidad del otro. Estar presente no significa simplemente "estar ahí,, sino que se caracteriza por su orientación hacia el otro. Marcel $(2005,27)$ afirma que la presencia está sostenida por 
RAMÓN MÍNGUEZ VALLEJOS, B. EDUARDO ROMERO SÁNCHEZ Y MARINA PEDREÑO PLANA

"la experiencia [...] y el sentimiento compartido de existir, de estar en el mundo». El educador se hace presente ante el otro cuando expresa con su comportamiento sentido de justicia, respeto por el otro, acogida y promoción del otro como persona. Y esta respuesta de cercanía es ética, a la vez que provisional y contingente.

- Buscar el bien del otro: La responsabilidad del educador para con el otro (educando) no termina con ofrecer "cualquier» respuesta. Sólo cuando el educador ha sido afectado por el otro, de modo que pueda ser minimizado y destruido como persona, estará en disposición de comprometerse en buscar el bien en el otro educando. El estar-ahí hacia el otro obliga a ser bueno con él y evita caer en egoísmo orgulloso. "El bien es el paso al otro, $[\ldots]$, donde el existir del otro me resulta más importante que el mío» (Poiré y Lévinas, 2009, 85). Lo que no se puede hacer es omitir el bien en el encuentro con el educando; si así fuera no habría acto educativo. Y hacer el bien puede ser interpretado por el educador como disponibilidad para actuar con solicitud de no consentir que el educando sea herido, ultrajado o humillado en su condición humana. Por ello, acciones como cuidar, atender, ayudar, acompañar o discernir, entre otras, están en la órbita de hacer el bien en el educando.

- Encontrarse con el otro: El hecho de hacerse cargo del educando exige no limitarse a educar a partir de su contexto, a cuidar de él y ser solícito a su demanda. Implica una actitud de mayor re-ligación con el otro. No siempre se acomete la ardua tarea de encontrarse con las preguntas e inquietudes que subyacen en la vida del educando, provocadoras de situaciones personales de discontinuidad y desarraigos. Encontrarse con el educando es tomar impulso y saltar a un escenario de mayor conciencia personal, de humanización y discernimiento afectivo. Es «educar desde la otra orilla», dirían Gárate y Ortega.

\subsection{Estilo educativo propio de la pedagogía de la alteridad}

A nuestro juicio, el estilo educativo que se deriva de esta pedagogía está determinado por dos valores: el diálogo y la compasión. Lévinas (2005) reclama un nuevo humanismo, aquel que se aleja de la razón egológica y se abre a la «razón del otro", un humanismo del otro hombre, lo que se podría traducir como aspirar a «una educación con rostro humano» (Gárate y Ortega, 2015, 237). Por ello, el diálogo como valor se convierte en signo ineludible de identidad de la pedagogía de la alteridad, asumido como presencia, escucha y respuesta dentro de la relación educativa, pero que sin la compasión como condición para identificarse con la situación, con el mundo de sentimientos, pensamientos y experiencias del otro alumno sería bastante difícil el comienzo de la aventura educativa.

Tanto el diálogo como la compasión nunca pueden ser asumidos como el cumplimiento de una orden ajena del acontecer educativo, sino que arranca de un 
espacio compartido en el que el yo (educador), afectado por el otro/educando, le responde de modo ético. "Es esta disposición de apertura al otro, de abandono y renuncia de sí mismo lo que hace que el otro me importe, me descentre para ponerme en el lugar del otro. Sólo así el maestro educa» (Gárate y Ortega, 2015, 180). Por ello, resulta decisivo que las aulas se conviertan en espacios de aprendizaje moral, expresión del encuentro, de la amistad, de la confianza y de la responsabilidad. Sin este ethos que orienta el modo de aprender juntos en las aulas será muy difícil que se llegue a educar.

\subsubsection{El diálogo en la pedagogía de la alteridad}

Un estilo dialogante remite al descubrimiento de la relación que existe entre ellos: educador y educando. Relación que lleva a la práctica de unas actitudes básicas: escucha y encuentro. El diálogo comienza siendo un espacio acogedor del otro a través de la palabra, del gesto y de la presencia. Lévinas utiliza una expresión muy gráfica: ¡Heme aquí! Y en él recoge el carácter solícito del educador. Sería como anteponer lo que «dice» el educando y prestarle atención. El educador ejerce la escucha cuando acoge la experiencia del otro/alumno, siempre personal y fragmentaria, como asunto propio. Ponerse a la escucha del otro es obedecer (del latín ob audire, escuchar al que está enfrente de mí, oír atentamente), practicar esa atención que me obliga a entregarme a una tarea diferente y siempre nueva, como si fuera algo único. Y de la escucha atenta se llega al encuentro.

Además, el diálogo incorpora otras actitudes. La primera es la generosidad, la actitud de disponibilidad y entrega del educador al educando. Y junto a ésta, van las de confianza y veracidad. Si el educador miente o no es generoso en presencia del otro, suscita desconfianza o deformación. En cambio, cuando hay confianza y es veraz, el educador es percibido como fiable. Se genera entonces una relación de intimidad y ello se traduce en fidelidad y cordialidad. Sólo de este modo se pone "Corazón" a la relación personal. "Cuando uno se abre a otra persona de modo cordial, su comunicarse es un decidido darse» (López Quintás, 2012, 23).

El diálogo así expuesto supera cualquier actividad intelectual de conversar en la búsqueda conjunta de la verdad. Dialogar, en sentido lévinasiano, se convierte en una actividad vital marcada por el carácter de acontecimiento y transformación que afecta directamente a las personas implicadas. Por ello, dialogar no es tomar la palabra en una conversación; es dejarse interpelar vitalmente por el otro (educando) que no le lleva a la indiferencia, sino que es interpelado o comprometido en la consecución del bien del otro. Además, el diálogo como ingrediente de la acción educativa reclama del educador la disposición a establecer una relación "amistosa" con el educando para ayudarle a "labrarse un porvenir» (Ibáñez-Martín, 2014, 88), amistad que sobrepasa una relación simplemente contractual. 
RAMÓN MÍNGUEZ VALLEJOS, B. EDUARDO ROMERO SÁNCHEZ Y MARINA PEDREÑO PLANA

\subsubsection{El aprendizaje de la compasión}

Una de las situaciones más difíciles en la educación de la alteridad es cómo responder ante el hecho del sufrimiento del otro. Al hablar de sufrimiento no nos referimos a situaciones injustas de millones de seres humanos inocentes por causas sobrevenidas, condenados a una inhumanidad que pone en tela de juicio nuestra humanidad. Aun siendo esas situaciones motivo para despertar la compasión, aquí nos centramos en cómo aprender a ser compasivos con el otro. Hablamos de compasión en el sentido que le atribuye Lévinas (1994, 134), como «une relation étrange qui commence dans le doleur..., dans celle de l'autre qui ne m'est pas indifférente. C'est l'amour de l'autre ou la compassion".

Si bien es cierto que en la raíz de muchos problemas humanos se encuentra una falsa compasión que por ella se elude la incómoda verdad de asumir responsabilidades, la demanda de amor o compasión en la actualidad se ha intensificado como reacción a la proliferación de actitudes egoístas y de indiferencia hacia la "herida» injusta del otro. La compasión, entendida como un modo de comprender al otro mediante la identificación afectiva, se ha convertido en un novedoso modelo de comportamiento como reacción a la ocultación del sufrimiento y a la cultura de la autosuficiencia (Audi, 2011).

No resulta fácil aprender a compadecer cuando los procesos educativos se aferran sólo a mostrar la cara más amable de la vida humana. Qué duda cabe de que queremos ser felices como derecho indiscutible. Y, sin embargo, no estamos libres de la experiencia del fracaso, del sufrimiento, de aquellas situaciones que parecen estar en contra de las justas pretensiones de cualquiera de nosotros. Frente a ello, la pregunta que suscita el pensamiento de Lévinas marca un giro decisivo. ¿Se puede compartir el sufrimiento? ¿Puedo sentir empatía con el que sufre? Ante la constatación de tanto sufrimiento injusto en personas a lo largo del tiempo, Lévinas nos recuerda que la compasión se alza como respuesta sensata y útil para identificarse con la situación, con el mundo de sentimientos y entender el modo de pensar y actuar del otro, como condición básica de las relaciones interpersonales en educación.

El primer paso en el itinerario educativo de la compasión es hacerse cargo de la realidad del otro sufriente tal cual es. No consiste en hacer una lectura intelectual de la misma, sino en acercarse a esa realidad tal cual es. Siempre será "esa", atrapada en un tiempo y en un espacio concreto. Sin embargo, hay impedimentos que nos evaden captar la realidad del sufriente. Son factores que repercuten negativamente y nos hacen insensibles ante el otro que sufre. La desmesurada velocidad de nuestro día a día, la falta de tiempo para la reflexión y la palabra acogedora, el carácter efímero de las relaciones interpersonales o la pérdida de confianza son algunas de las condiciones que impiden ver "lo que hay que ver". Algunos se refieren a la complejidad de los procesos educativos, otros a variables económicas, sociológicas, psicológicas, etc. Frente a discursos técnicos neutrales, hacerse cargo de la realidad sufriente reclama la pasión por lo evidente: que el otro sufre. 
El siguiente paso es cargar con la realidad de la persona que sufre. Ello implica padecer-con el otro, aligerar su sufrimiento y compartir su situación. Acciones como acercarse, arriesgarse o cuidar determinan el sentido compasivo de la ayuda al otro. En el terreno educativo, hay compasión cuando el maestro siente dolor por la situación de sufrimiento del alumno y no le resulta indiferente. El alumno puede sentirse vulnerado por ignorancia, por la ausencia de conocimientos y su resistencia a querer aprenderlos; también por la tendencia a comportarse de modo errático o por la debilidad del carácter que le lleva a comportarse de modo no deseable.

Acercarse y tomar partido por su sufrimiento, contribuir a mejorar su valía personal, descubrir sus capacidades, orientar sus decisiones son acciones que podrían agruparse en una palabra, hospedar. La tarea de hospedar en educación consiste en acoger al diferente, mostrar afecto no desmesurado y determinación por la búsqueda de la verdad y el bien del otro. Acoger en educación conecta con algo peculiar de nuestra condición humana: «Nuestra existencia quebradiza y frágil, necesitada y dependiente» (Innerarity, 2001, 28).

Pero el aprendizaje de la compasión no debe reducirse solo a la realización de acciones asistenciales o rehabilitadoras de la situación concreta del otro. La compasión enseña a ir más allá de atender a las carencias que le hacen sufrir. Estamos en el tercer paso: encargarse de la realidad para aspirar a otra realidad que genere menos sufrimiento. La necesidad de construir un nuevo estilo de educar contribuiría a superar la acción intimista de la compasión. Con ello, aparece la oportunidad de priorizar en los objetivos y tareas que aspiran a hacer realidad otra educación. Para eso no está de más volver a preguntarse ¿para qué educar? Sin olvidar que, para nosotros, sin ética no hay educación y la ética que aquí reclamamos es esencialmente responsabilidad. Sería oportuno encontrar respuestas a preguntas tales como ¿para qué nuestras escuelas? ¿Para ofrecer «productos a sus clientes» o la búsqueda de la excelencia? ¿Para transmitir unos valores y conocimientos o para ser cuna de otros nuevos? ¿Educar para la competencia y el éxito a costa de otros o educar para que sea testimonio de otra forma de ser humanos? Encargarse de la realidad de la educación exige actitudes más decididas que logren superar algunos clichés arraigados en la práctica cotidiana de educar.

\section{4. Último PUNTO}

Educar conforme a la pedagogía del otro nos plantea una pregunta inevitable: ¿quién es el otro/alumno para mí? ¿Qué relación establezco con él? Sólo en la medida en que sea reconocido como alguien, habrá posibilidad de educar. Ello nos aleja de una visión abstracta de la educación desde la que han sido formadas muchas generaciones. También nos separa de una educación que deriva de un deber o legalidad, como si tuviese que ajustarse al cumplimiento de unos principios o normas que regulan la actividad del educador. Y nos separa de un modo de ver al educando como un objeto, como si fuera un simple depositario de saberes, 
en la pretensión de controlar las principales variables que intervienen en la adquisición de conocimientos y habilidades que garantizan el éxito de la tarea educadora.

La educación que emana de la pedagogía del otro es ética, no científica ni idealista. Parte del supuesto de que educar es hacerse cargo del otro en su fragilidad, de responderle como ser vulnerable. En tanto que cualquier ser humano está expuesto a cualquier tipo de fractura y puede quedar truncada su posibilidad de llegar a ser alguien valioso. La práctica educativa de esta pedagogía está relacionada con la transmisión de la vida y su cultivo, especialmente con las generaciones futuras. Por lo que educar es responder a este otro en su situación, cuando el educador se preocupa y ocupa de él. Ello implica tanto la práctica de la compasión, el reconocimiento del otro necesitado de mi ayuda, como también el ejercicio de la responsabilidad como camino de reconocimiento de la alteridad y relación con los otros.

\section{REFERENCIAS BIBLIOGRÁFICAS}

Audi, P. (2011) L'empire de la compassion. Le Kremlin-Bicêtre (France), Les Belles Lettres.

BÁRCENA, F. (2012) Una pedagogía de la presencia: crítica filosófica de la impostura pedagógica. Teoría de la Educación. Revista Interuniversitaria, 24 (2), 25-57.

Beorlegui, C. (1998) El pensamiento ético-antropológico de E. Lévinas. Su fecundidad y sus insuficiencias. Letras de Deusto, 28 (78), 143-172.

Biesta, G. (2008) Pedagogy with Empty Hands. Lévinas, Education and the Question of Being Human. En EgÉA-KueHne, D. (ed.) Lévinas and Education. At the intersection of Faith and Reason. New York, Routledge, 198-210.

ButLer, J. (2006) Vida precaria. Buenos Aires, Paidós.

Butler, J. (2009) Dar cuenta de sí mismo. Violencia ética y responsabilidad. Buenos Aires, Amorrortu.

Chalier, C. (1995) La utopia de lo humano. Madrid, Riopiedras.

Chinnery, A. (2010) Encountering the philosopher as teacher: The pedagogical postures of Emmanuel Lévinas. Teaching and Teacher Education, 26, 1704-1709. Doi:10.1016/j. tate.2010.06.023.

DERRIDA, J. (1989) La escritura y la diferencia. Barcelona, Anthropos.

Descombes, V. (1988) Lo mismo y lo otro: cuarenta y cinco años de filosofía francesa (19331978). Madrid, Cátedra.

EgÉA-Kuehne, D. (ed.) (2008) Lévinas and Education. At the intersection of Faith and Reason. New York, Routledge.

EsCÁMEZ, J. (1981) Fundamentación antropológica de la educación, en CASTILlejO, J. L.; EsCÁMEZ, J. y Marín, R. (eds.) Teoría de la Educación. Madrid, Anaya, 7-27.

Fullat, O. (1997) Antropología filosófica de la educación. Barcelona, Ariel.

Gárate, A. y Ortega, P. (2015) Educar desde la precariedad. La otra educación posible. Madrid, Ápeiron Eds.

García-BARÓ, M. (2012) Elementos de antropología filosófica. Morelia (México), Jitanjáfora Ed.

Hand, S. (ed.) (1989) The Lévinas reader. Oxford (MA), Blackwell.

HAND, S. (2009) Emmanuel Lévinas. London, Routledge. 
RAMÓN MÍNGUEZ VALLEJOS, B. EDUARDO ROMERO SÁNCHEZ Y MARINA PEDREÑO PLANA

LA PEDAGOGÍA DEL OTRO: BASES ANTROPOLÓGICAS E IMPLICACIONES EDUCATIVAS

Hanus, G. (2012) Échapper à la philosophie? Lecture de Lévinas. Lagrasse (France), Verdier. IbÁÑEZ-MarTín, J. A. (2014) Europa: la sabiduría y sus apariencias. La pedagogía del deseo y las disposiciones intelectuales. Revista Española de Pedagogía, 257, 77-92.

InNerarity, D. (2001) Ética de la hospitalidad. Barcelona, Península.

Joldersma, C. W. (2014) A Levinasian Ethics for Education's Commonplaces. New York, Palgrave MacMillan.

KANT, I. (1990) Fundamentación de la metafísica de las costumbres. Madrid, Espasa Calpe.

LÉVINAS, E. (1994) Une éthique de la souffrance-entretien avec Emmanuel Lévinas, en Souffrances, corps et âme, épreuves partagées. Paris, Autrement, 133-135.

LÉVINAS, E. (2000) Ética e infinito. Madrid, Machado libros.

LÉVINAS, E. (2001) Entre nosotros. Valencia, Pre-Textos.

LÉvinas, E. (2002) Totalidad e infinito. Tratado sobre la exterioridad. Salamanca, Sígueme.

LÉvinas, E. (2003) De otro modo que ser o más allá de la esencia. Salamanca, Sígueme.

LÉvinAs, E. (2005) Humanismo del otro hombre. México, Siglo XXI.

LÉvinas, E. (2006a) Los imprevistos de la historia. Salamanca, Sígueme.

LÉVINAS, E. (2006b) De la existencia al existente. Madrid, Arena libros.

LÉvinas, E. (2010) L'actualité de Maïmonide. Cabiers d'études lévinassiennes, 9, 195.

López QuinTás, A. (2012) El descubrimiento del amor auténtico. Claves para orientar la afectividad. Madrid, BAC.

LyotaRd, J. F. (2015) Logique de Lévinas. Lagrasse (France), Verdier.

MARCEL, G. (2001) Los hombres contra lo bumano. Madrid, Caparrós eds.

MARCEL, G. (2005) Homo viator. Salamanca, Sígueme.

Marzano, M. (2011) Programados para triunfar. Barcelona, Tusquets.

Masschelein, J. y Simons, M. (2013) In defense of the School. A Public Issue. Leuven, E-ducation, Culture \& Society Publishers.

MÈLICH, J. C. (2010) Ética de la compasión. Barcelona, Herder.

MÈLICH, J. C. (2014) La condición vulnerable (Una lectura de Emmanuel Lévinas, Judith Butler y Adriana Cavarero). Ars Brevis, 20, 313-335

Mínguez, R. (2012) La responsabilidad educativa en tiempos de crisis. Edetania: Estudios y Propuestas Socio-educativas, 42, 107-125.

Ortega, P. (2010) Educar es responder a la pregunta del otro. Edetania: Estudios y Propuestas Socio-educativas, 37, 13-31.

Ortega, P. (2016) La ética de la compasión en la pedagogía de la alteridad. Revista Española de Pedagogía, 264, 243-264.

PiePER, J. (2000) Obras. Volumen 3: Escritos sobre el concepto de filosofía. Madrid, Eds. Encuentro.

PoIré, F. y LÉvinas, E. (2009) Ensayo y conversaciones. Madrid, Arena libros.

PrieTo, M. (2011) La vida afectiva en la Teoría de la Educación. El tratamiento de las emociones en el Seminario Interuniversitario de Teoría de la Educación. Teoría de la Educación. Revista Interuniversitaria, 23 (1), 107-129.

SACHS, J. (2011) The Price of Civilization: Reawakening America Virtue and Prosperity. New York, Random House.

SaHagún, J. (1996) Las dimensiones del hombre. Antropología filosófica. Salamanca, Sígueme. Soffer, G. (1999) The Other as Alter Ego: A Genetic Approach. Husserl Studies, 15, 151-166. Steiner, G. (1998) En el Castillo de Barba Azul. Aproximación a un nuevo concepto de cultura. Madrid, Gedisa. 
RAMÓN MÍNGUEZ VALLEJOS, B. EDUARDO ROMERO SÁNCHEZ Y MARINA PEDREÑO PLANA

Strhan, A. (2012) Lévinas, Subjectivity, Education. Towards an Ethics of Radical Responsibility. Chichester (UK), Wiley-Blackwell.

Unamuno, M. (1958) Ensayos II. Madrid, Aguilar.

WALDENFELS, B. (2015) Exploraciones fenomenológicas acerca de lo extraño. Barcelona, Anthropos.

ZHAO, G. (2016) Lévinas and the Pshilosophy of Education. Educational Philosophy and Theory, 48 (2), 323-330. Disponible en http://dx.doi.org//10.1080/00131857.2015.104 1007. 